\title{
The effect of 6-chloro-6-deoxysugars on adenine nucleotide concentrations in and motility of rat spermatozoa
}

\author{
W. C. L. Ford and Anne Harrison \\ Department of Physiology \& Biochemistry, The University, Whiteknights, Reading RG6 2AJ, \\ U.K.
}

\begin{abstract}
Summary. Spermatozoa from rats treated with 6-chloro-6-deoxyglucose (120 $\mu \mathrm{mol} / \mathrm{kg} /$ day) were as motile as those from controls soon after dilution but rapidly became immotile when $2 \mathrm{mM}$-D-glucose was the only substrate present. Control spermatozoa were more motile when 2 mM-pyruvate +4 mM-DL-lactate rather than 2 mM-D-glucose was present and the former substrate allowed spermatozoa from treated rats to remain motile.

The concentrations of the adenine nucleotides declined rapidly during $40 \mathrm{~min}$ incubations when the substrate was $2 \mathrm{~mm}$-D-glucose. The ATP/ADP ratio and the energy charge (ATP + $\frac{1}{2}$ ADP/ATP + ADP + AMP) were maintained in spermatozoa from control rats but not in those from treated rats. When the substrate was $2 \mathrm{~mm}$-pyruvate $+4 \mathrm{~mm}$-DL-lactate adenine nucleotides were not lost as rapidly and there was less difference between spermatozoa from control and treated rats.
\end{abstract}

\section{Introduction}

The 6-chloro-6-deoxysugars and $\alpha$-chlorohydrin have a reversible antifertility action in the male rat. It is believed that this may be caused by the inhibition of glycolysis in spermatozoa (see Jones, 1978; Ford, Harrison \& Waites, 1981). This hypothesis is supported by the observation that the ATP concentration declines more rapidly in spermatozoa from animals treated with these compounds than in those from controls when the cells are incubated in vitro with glucose or fructose as the only substrate (Brown-Woodman, Mohri, Mohri, Suter \& White, 1978; Ford \& Waites, 1978; Ford, Harrison, Takkar \& Waites, 1979). However, treatment of rats with 6-chloro-6-deoxyglucose had no effect on the stimulation of oxygen uptake by lactate, pyruvate, succinate or glycerol 3-phosphate (Ford et al., 1981). Ram spermatozoa incubated with sufficient $\alpha$-chlorohydrin to inhibit fructose metabolism could still oxidize lactate, pyruvate or acetate (Brown-Woodman et al., 1978).

We have now attempted to correlate the motility of spermatozoa from rats treated with 6-chloro-6-deoxyglucose with the concentrations of adenine nucleotides in the cells and their energy charge (ATP + $\frac{1}{2}$ ADP $/$ ATP + ADP + AMP) (Atkinson \& Walton, 1967).

\section{Materials and Methods}

The sources of materials and of rats were as described by Ford et al. (1981).

For Exp. 1, groups of 6 male rats $(350 \mathrm{~g}$ body wt) were dosed orally with 6-chloro6-deoxyglucose $(0,20,50$ or $120 \mu \mathrm{mol} / \mathrm{kg} / \mathrm{day})$ for 14 days. These doses were associated with 
no overt effect on sperm glycolysis or fertility $(20 \mu \mathrm{mol})$, decreased glycolysis but no effect on fertility $(50 \mu \mathrm{mol})$ and marked inhibition of both glycolysis and fertility $(120 \mu \mathrm{mol})$. The fertility of the rats was assessed as described previously (Ford et al., 1981). The male rats were killed one at a time on Day 15 and the spermatozoa were flushed from each cauda epididymidis simultaneously, using phosphate-buffered physiological saline (PBS) (Ford et al., 1981) which contained 2 mM-D-glucose. The buffer ( $\mathrm{pH} 7.4$ ) was freshly prepared from concentrated stock solutions or was stored overnight at $4^{\circ} \mathrm{C}$. It was used at room temperature. The spermatozoa $\left(27-163 \times 10^{6}\right)$ were dispersed in $2.5 \mathrm{ml}$ buffer. A $5 \mu \mathrm{l}$ sample of the suspension was removed for the measurement of motility (Dott \& Foster, 1979) and simultaneously $0.70 \mathrm{ml}$ was mixed with $0.35 \mathrm{ml} 1 \mathrm{M}$-perchloric acid. These samples for the 'zero time' data were taken 1-2 min after dilution of the epididymal spermatozoa and 4-7 min after the death of the rat. The rest of the sperm suspension was incubated in a shaking water bath at $35^{\circ} \mathrm{C}$ and subsequent samples were removed after 20 and $40 \mathrm{~min}$. The acidified samples were stored on ice and neutralized as described previously (Ford et al., 1981), the volumes of reagents being adjusted accordingly.

For Exp. 2, 8 male $\mathrm{CD}$ rats $(350 \mathrm{~g}$ body $\mathrm{wt}$ ) were treated orally with 6-chloro6-deoxyglucose $(120 \mu \mathrm{mol} / \mathrm{kg} /$ day $)$ for 14 days and 8 untreated rats acted as controls. Only one epididymis per rat was used and the spermatozoa were flushed out of 4 rats in each group with PBS buffer which contained $2 \mathrm{~mm}$-sodium pyruvate plus $4 \mathrm{~mm}$-sodium-DL-lactate. PBS buffer which contained 2 mM-D-glucose was used for the remaining rats. The spermatozoa were dispersed in $1.0 \mathrm{ml}$ buffer and $5 \mu \mathrm{l}$ samples were removed after incubation for 0,30 and $60 \mathrm{~min}$ at $35^{\circ} \mathrm{C}$. A further 2 groups each of 8 rats were treated similarly except that spermatozoa from both epididymides were collected, the total volume in the incubation flask was $2.5 \mathrm{ml}$ and $0.7 \mathrm{ml}$ samples were removed after 0,20 and 40 min incubation at $35^{\circ} \mathrm{C}$.

ATP, ADP and AMP were measured fluorometrically in all the samples in Exp. 1 and the latter part of Exp. 2 (Williamson \& Corkey, 1969).

\section{Results}

\section{Experiment 1}

Rats treated with 6-chloro-6-deoxyglucose $(<50 \mu \mathrm{mol} / \mathrm{kg} /$ day) remained fully fertile and their spermatozoa were motile throughout a 40 -min incubation when $2 \mathrm{mM}$-D-glucose was the only substrate added (Table 1). When the dose of 6-chloro-6-deoxyglucose was increased to 120 $\mu \mathrm{mol} / \mathrm{kg} / \mathrm{day}$ the rats became infertile and the spermatozoa rapidly became immotile in these incubation conditions although motility was normal at zero time (Table 1).

Table 1. The motility of epididymal spermatozoa from rats given 6-chloro-6-deoxyglucose for 14 days and the conception rate in females paired with them

\begin{tabular}{|c|c|c|c|c|}
\hline \multirow[b]{2}{*}{ Dose $(\mathrm{mol} / \mathrm{kg} /$ day $)$} & \multicolumn{3}{|c|}{ Sperm motility ${ }^{\dagger}$} & \multirow[b]{2}{*}{ Conception rate $(\%) \dagger$} \\
\hline & $0 \mathrm{~min}$ & $20 \mathrm{~min}$ & $40 \mathrm{~min}$ & \\
\hline 0 & $26 \cdot 1 \pm 4 \cdot 7$ & $25 \cdot 3 \pm 4 \cdot 0$ & $16.8 \pm 4.4$ & 95.6 \\
\hline 20 & $18.6 \pm 3.4$ & $23.8 \pm 4.4$ & $20.5 \pm 2.9$ & $96 \cdot 7$ \\
\hline 50 & $18 \cdot 1 \pm 3 \cdot 2$ & $16.8 \pm 4.9$ & $11 \cdot 2 \pm 4 \cdot 1$ & $94 \cdot 0$ \\
\hline 120 & $22.8 \pm 4.9$ & $1.4 \pm 1 \cdot 1^{* * *}$ & $1.9 \pm 1.3^{* *}$ & $4 \cdot 2$ \\
\hline
\end{tabular}

† Measured by the area change frequency procedure (Dott \& Foster, 1979). Values are mean \pm s.e.m. for 6 rats.

$\ddagger($ Live + resorbing embryos $) /$ no. of corpora lutea $) \times 100$. Values are means for 6 females.

Values significantly different from controls: ${ }^{* *} P<0.01$, ${ }^{* * *} P<0.001$ ( $t$ test). 


\section{Experiment 2}

Spermatozoa supplied with pyruvate and lactate were more vigorously motile than when glucose was the only substrate present (Table 2). Spermatozoa from treated rats remained motile for $40 \mathrm{~min}$ when pyruvate plus lactate was present but motility declined when only glucose was added to the medium (Table 2).

Table 2. The effect of substrate on the motility of epididymal spermatozoa from rats given 6-chloro-6deoxyglucose

\begin{tabular}{|c|c|c|c|c|}
\hline \multirow[b]{2}{*}{ Treatment } & \multirow[b]{2}{*}{ Substrate } & \multicolumn{3}{|c|}{ Motility (area change frequency) } \\
\hline & & $0 \mathrm{~min}$ & $30 \mathrm{~min}$ & $60 \mathrm{~min}$ \\
\hline \multirow[t]{2}{*}{ Control } & 2 mM-D-Glucose & $17 \cdot 7 \pm 6 \cdot 2$ & $\begin{array}{c}10 \cdot 6 \pm 8 \cdot 1 \\
(60)\end{array}$ & $\begin{array}{c}13 \cdot 6 \pm 4 \cdot 2 \\
(77)\end{array}$ \\
\hline & $\begin{array}{c}2 \text { mM-Pyruvate }+ \\
4 \text { mM-DL-lactate }\end{array}$ & $28 \cdot 3 \pm 3 \cdot 8$ & $\begin{array}{l}31 \cdot 2 \pm 2 \cdot 5^{*} \\
\quad(110)\end{array}$ & $\begin{array}{c}25 \cdot 9 \pm 6 \cdot 4 \\
(91)\end{array}$ \\
\hline \multirow[t]{2}{*}{$\begin{array}{l}\text { 6-Chloro-6-deoxyglucose } \\
(120 \mu \mathrm{mol}(24 \mathrm{mg}) / \mathrm{kg} / \mathrm{day})\end{array}$} & 2 mM-D-Glucose & $25 \cdot 3 \pm 8 \cdot 7$ & $\begin{array}{c}6.5 \pm 2.9 \\
(26)\end{array}$ & $\begin{array}{c}3 \cdot 7 \pm 3 \cdot 3 \\
(15)\end{array}$ \\
\hline & $\begin{array}{c}2 \text { mM-Pyruvate }+ \\
4 \text { mM-DL-lactate }\end{array}$ & $24 \cdot 1 \pm 6 \cdot 0$ & $\begin{array}{c}15 \cdot 7 \pm 6 \cdot 4 \\
(65)\end{array}$ & $\begin{array}{l}18 \cdot 4 \pm 4 \cdot 9^{*} \\
(76)\end{array}$ \\
\hline
\end{tabular}

Values are mean \pm s.e.m. for 4 rats, with the percentage motility compared with that at zero time in parentheses.

* Significantly different from value for spermatozoa incubated with glucose, $P<0.05$ ( $t$ test).

The concentration of adenine nucleotides in the spermatozoa declined markedly during the incubation and ATP was lost more rapidly than ADP or AMP (Table 3). The loss of ATP and of total adenine nucleotide in the control spermatozoa was significantly slower in the presence of pyruvate + lactate than in the presence of glucose. Spermatozoa from treated rats showed a more rapid decline of these substances when glucose was the substrate, but treatment with 6-chloro-6-deoxyglucose had no effect on the changes when the substrate was pyruvate + lactate.

Table 3. The effect of incubation with $2 \mathrm{mM}-\mathrm{D}$-glucose or with $2 \mathrm{mM}$-pyruvate $+4 \mathrm{mM}$-DL-lactate on the adenine nucleotide concentration $\left(\mathrm{nmol} / 10^{8}\right.$ spermatozoa) in spermatozoa from rats treated with 6-chloro6-deoxyglucose $(120 \mu \mathrm{mol} / \mathrm{kg} /$ day $)$

\begin{tabular}{|c|c|c|c|c|c|c|c|c|c|c|c|c|}
\hline \multirow[b]{3}{*}{ Incubation time (min) } & \multicolumn{6}{|c|}{ Control rats } & \multicolumn{6}{|c|}{ Treated rats } \\
\hline & \multicolumn{3}{|c|}{ Glucose $(N=10)$} & \multicolumn{3}{|c|}{ Pyruvate + lactate $(\mathrm{N}=4)$} & \multicolumn{3}{|c|}{ Glucose $(N=10)$} & \multicolumn{3}{|c|}{ Pyruvate + lactate $(N=4)$} \\
\hline & 0 & 20 & 40 & 0 & 20 & 40 & 0 & 20 & 40 & 0 & 20 & 40 \\
\hline ATP & $\begin{array}{l}114 \pm \\
8.2\end{array}$ & $\begin{array}{l}22 \pm \\
5 \cdot 1\end{array}$ & $\begin{array}{l}15 \pm \\
4 \cdot 1\end{array}$ & $\begin{array}{l}114 \pm \\
15.2\end{array}$ & $\begin{array}{l}88 \pm \\
15.5 \S\end{array}$ & $\begin{array}{l}42 \pm \\
13.1 \dagger\end{array}$ & $\begin{array}{l}74 \pm \\
3 \cdot 7^{* * *}\end{array}$ & $\begin{array}{l}9 \pm \\
2 \cdot 0^{m}\end{array}$ & $5 \pm$ & $\begin{array}{l}101 \pm \\
13.2 \dagger\end{array}$ & $\begin{array}{l}66 \pm \\
15.7 \S\end{array}$ & $\begin{array}{l}34 \pm \\
12.97\end{array}$ \\
\hline ADP & $\begin{array}{l}70 \pm \\
7.8\end{array}$ & $\begin{array}{l}23 \pm \\
2 \cdot 8\end{array}$ & $\begin{array}{l}10 \pm \\
2 \cdot 1(9)\end{array}$ & $\begin{array}{l}36 \pm \\
5 \cdot 2 t\end{array}$ & $\begin{array}{l}22 \pm \\
2.6\end{array}$ & $\begin{array}{l}12 \pm \\
2 \cdot 4\end{array}$ & $\begin{array}{l}55 \pm \\
3.7\end{array}$ & $\begin{array}{l}15 \pm \\
2 \cdot 4^{4}\end{array}$ & $\begin{array}{l}8 \pm \\
2 \cdot 3\end{array}$ & $\begin{array}{l}28 \pm \\
6.87\end{array}$ & $\begin{array}{l}18 \pm \\
3 \cdot 1\end{array}$ & $\begin{array}{l}9 \pm \\
2 \cdot 3\end{array}$ \\
\hline AMP & $\begin{array}{l}18 \pm \\
6.1\end{array}$ & $\begin{array}{l}10 \pm \\
1.3\end{array}$ & $\begin{array}{l}5 \pm \\
0.6\end{array}$ & $\begin{array}{l}15 \pm \\
3.5\end{array}$ & $\begin{array}{l}9 \pm \\
2 \cdot 4\end{array}$ & $\frac{5 \pm}{1 \cdot 2}$ & $\begin{array}{l}23 \pm \\
2.8\end{array}$ & $\begin{array}{l}8 \pm \\
1 \cdot 3\end{array}$ & $\begin{array}{l}5 \pm \\
0.8\end{array}$ & $\begin{array}{l}13 \pm \\
4 \cdot 2\end{array}$ & $\begin{array}{l}10 \pm \\
1.7\end{array}$ & $\begin{array}{l}5 \pm \\
0.9\end{array}$ \\
\hline$A T P+A D P+A M P$ & $\begin{array}{l}202 \pm \\
13.9\end{array}$ & $\begin{array}{l}55 \pm \\
6 \cdot 3\end{array}$ & $\begin{array}{l}28 \pm \\
6.4(9)\end{array}$ & $\begin{array}{l}165 \pm \\
22.0\end{array}$ & $\begin{array}{l}118 \pm \\
17.8 \S\end{array}$ & $\begin{array}{l}58 \pm \\
15 \cdot 1\end{array}$ & $\underset{7 * *}{153 \pm}$ & $\begin{array}{l}33 \pm \\
4 \cdot 2^{* *}\end{array}$ & $\begin{array}{l}19 \pm \\
4 \cdot 1\end{array}$ & $\begin{array}{l}143 \pm \\
19.5\end{array}$ & $\begin{array}{l}94 \pm \\
15.9 \S\end{array}$ & $\begin{array}{l}48 \pm \\
14 \cdot 1 \dagger\end{array}$ \\
\hline ATP/ADP & $\begin{array}{l}1.8 \pm \\
0.17\end{array}$ & $\begin{array}{l}1.0 \pm \\
0.20\end{array}$ & $\begin{array}{l}1.5 \pm \\
0.52\end{array}$ & $\begin{array}{l}3.4 \pm \\
0.53 \ddagger\end{array}$ & $\begin{array}{l}4.2 \pm \\
0.76 \S\end{array}$ & $\begin{array}{l}3.6 t \\
0.7 t\end{array}$ & $\begin{array}{l}1.4 \pm \\
0.12\end{array}$ & $\begin{array}{l}0.66 \pm \\
0.12\end{array}$ & $\begin{array}{l}0.84 \pm \\
0.18\end{array}$ & $\begin{array}{l}3.9 \pm \\
0.678\end{array}$ & $\begin{array}{l}3.9 \pm \\
1.0 \$\end{array}$ & $\begin{array}{l}3.4 \pm \\
1.03 \ddagger\end{array}$ \\
\hline
\end{tabular}

Values are mean \pm s.e.m. for the no. of rats indicated in parentheses.

Values significantly different from those for control rats and the equivalent substrate: ${ }^{*} P<0.05,{ }^{* *} P<0.01,{ }^{* * *} P<0.001(t$ test).

Values significantly different from those for treated rats and the glucose substrate: $+P<0.05, \ddagger P<0.01, \S P<0.001(t$ test).

The ATP/ADP ratio and the energy charge (ATP + $\frac{1}{2}$ ADP/ATP + ADP + AMP) in the spermatozoa were significantly higher in the presence of pyruvate + lactate than when glucose was the substrate. The values were constant during the $40-\mathrm{min}$ incubation in control 
spermatozoa incubated with pyruvate + lactate and declined by a much smaller proportion than did the total adenine nucleotide concentration in the other groups. However, the energy charge in spermatozoa from treated rats was significantly lower than in the corresponding controls and continued to decline throughout the incubation.

Both motility and the adenine nucleotide concentrations were measured in the samples in Exp. 1. No correlations could be demonstrated in the zero time samples. In the samples taken at 20 or 40 min motility was correlated with the concentration of ATP $(20 \mathrm{~min}, r=0.66, P<$ $0.001 ; 40 \mathrm{~min}, r=0.69, P<0.001)$, the ATP/ADP ratio $(20 \mathrm{~min}, r=0.41 ; P<0.02 ; 40 \mathrm{~min}$, $r=50, P<0.02)$ and the energy charge (20 $\mathrm{min}, r=0.54, P<0.01 ; 40 \mathrm{~min}, r=0.54, P<$ 0.01 ); but the strongest correlation was with the total adenine nucleotide concentration (20 $\min , r=0.78, P<0.001 ; 40 \mathrm{~min}, r=0.69, P<0.001)$ ( 22 d.f. in each case).

\section{Discussion}

A most striking feature of the results is the decline in the concentrations of sperm adenine nucleotides during the incubations. In most cells the ratios between the different nucleotides may change considerably but their sum remains comparatively constant except under conditions of severe stress. This raises doubts about the viability of rat spermatozoa under these incubation conditions. A large proportion of spermatozoa from control rats remained motile for up to 60 $\min$ (Tables 1 and 2) and glucose oxidation could continue at a constant rate for up to $2 \mathrm{~h}$ (Ford \& Waites, 1978). Few dead cells could be detected by live/dead staining with eosin-nigrosin in suspensions of spermatozoa from control or treated rats but this technique may be unsatisfactory with these spermatozoa (Turner, D'Addario \& Howards, 1978). A similar loss of adenine nucleotides occurs in hamster spermatozoa (Rogers \& Morton, 1972; W. C. L. Ford \& A. Harrison, unpublished results). We therefore believe that valid comparisons can be made between spermatozoa from rats treated with 6-chloro-6-deoxyglucose and controls, but the physiological significance of the decline in adenine nucleotide concentration will be uncertain until it has been demonstrated under conditions in which the spermatozoa are known to be fertile.

The observations on the motility of spermatozoa and their energy charge are consistent with the hypothesis that treatment with 6-chloro-6-deoxysugars produces a lesion in the glycolytic pathway of affected spermatozoa which makes them unable to obtain energy from glucose.

Although no evidence is available for the rat, pyruvate and lactate are present in fluids secreted by the uterus and the oviduct in rabbits, ewes and sows (Iritani, Gomes \& VanDemark, 1969; Iritani, Nishikawa, Gomes \& VanDemark, 1971; Iritani, Sato \& Nishikawa, 1974; Leese \& Aldridge, 1979). Moreover, adequate oxygen is available in the uterus (Nevo, 1965; Yedwab, Paz, Homonnai, Menahem \& Kraicer, 1976), and, based on the criteria of motility and energy charge, pyruvate plus lactate is a more effective substrate for rat spermatozoa than glucose. Therefore, if the inhibition of glucose metabolism in spermatozoa by treatment with 6-chloro-6-deoxysugars is the sole cause of infertility, then glucose metabolism must play some role in fertility apart from the regeneration of those pools of ATP large enough to be detected by our techniques. The presence of glucose was necessary for optimal results in the in-vitro fertilization of rat eggs (Tsunoda \& Chang, 1975; Niwa \& Iritani, 1978) but despite reports to the contrary (see Hoppe, 1976) there is considerable evidence that lactate + pyruvate is adequate for the capacitation of mouse, hamster and guinea-pig spermatozoa (see Rogers, 1978). It is at present impossible to decide whether glucose has a special role in the fertility of spermatozoa or if a lesion outwith the glycolytic pathway is responsible for the antifertility action of the 6-chloro-6-deoxysugars and $\alpha$-chlorohydrin.

The interpretation of the adenine nucleotide data is complicated by several factors including partitioning between cellular compartments, binding of ADP to proteins, changes in the $\mathrm{Mg}^{2+}$ concentration and differences in the concentration of ATP and ADP along the flagellum (Nevo 
\& Rikmanspoel, 1970). Nevertheless, the energy charge and ATP/ADP ratio remain fairly stable despite the enormous changes in the size of the adenine nucleotide pools. It is possible that the energy potential in the adenine nucleotide pools could limit the motility of these spermatozoa. The motility of bovine spermatozoa was correlated with the ATP concentration in the cells (Foulkes \& Macdonald, 1979). However, this is not the only factor involved since there was no relationship between motility and energy charge at zero time.

We thank Dr H. M. Dott for the measurements of sperm motility; Miss P. M. Rummings for technical assistance with the animal experiments; and Professor G. M. H. Waites for discussion. This work was supported by grants (No. 75311 and No. 77127) from the World Health Organisation.

\section{References}

Atkinson, D.E. \& Walton, G.M. (1967) Adenosine triphosphate conservation in metabolic regulation. $J$. biol. Chem. 242, 3239-3241.

Brown-Woodman, P.D.C., Mohri, H., Mohri, T., Suter, D. \& White, I.G. (1978) Mode of action of a-chlorohydrin as a male antifertility agent. Biochem. J. 170, 23-37.

Dott, H.M. \& Foster, G.C.A. (1979) The estimation of sperm motility in semen, on a membrane slide, by measuring the area change frequency with an image analysing computer. J. Reprod. Fert. 55, 161-166.

Ford, W.C.L. \& Waites, G.M.H. (1978) Chlorinated sugars: a biochemical approach to the control of male fertility. Int. J. Androl., Suppl. 2, 541-564.

Ford, W.C.L., Harrison, A., Takkar, G.L. \& Waites, G.M.H. (1979) Inhibition of glucose catabolism in rat, hamster, rhesus monkey and human spermatozoa by a-chlorohydrin. Int. J. Androl. 2, 275-288.

Ford, W.C.L., Harrison, A. \& Waites, G.M.H. (1981) Effects of 6-chloro-6-deoxysugars on glycolysis in rat spermatozoa. J. Reprod. Fert. 63, 67-73.

Foulkes, J.A. \& Macdonald, B.J. (1979) The relationship between the ATP content and motility of bovine spermatozoa. Theriogenology 11, 313-319.

Hoppe, P.C. (1976) Glucose requirement for mouse sperm capacitation in vitro. Biol. Reprod. 15, 39-45.

Iritani, A., Gomes, W.C. \& VanDemark, N.L. (1969) Secretion rates and chemical composition of oviduct and uterine fluids in ewes. Biol. Reprod. 1, 72-76.

Iritani, A., Nishikawa, Y., Gomes, W.R. \& VanDemark, N.L. (1971) Secretion rates and chemical composition of oviduct and uterine fluid in rabbits. $J$. Anim. Sci. 33, 829-835.

Iritani, A., Sato, H. \& Nishikawa, Y. (1974) Secretion rates and chemical composition of oviduct and uterine fluids in sows. J. Anim. Sci. 39, 582-588.

Jones, A.R. (1978) The antifertility actions of $\alpha$ - chlorohydrin in the male. Life Sciences 23, 16251646.

Leese, H.J. \& Aldridge, S. (1979) The movement of pyruvate, lactate and lactate dehydrogenase into rabbit oviductal fluid. J. Reprod. Fert. 56, 619-622.

Nevo, A.C. (1965) Dependence of sperm motility and respiration on oxygen concentration. J. Reprod. Fert. 9, 103-107.

Nevo, A.C. \& Rikmanspoel, R. (1970) Diffusion of ATP in sperm flagella. J. theoret. Biol. 26, 11-18.

Niwa, K. \& Iritani, A. (1978) Effect of various hexoses on sperm concentration and penetration of rat eggs in vitro. J. Reprod. Fert. 53, 267-271.

Rogers, B.J. (1978) Mammalian sperm capacitation and fertilization in vitro: a critique of methodology. Gamete Res. 1, 165-223.

Rogers, B.J. \& Morton, B.E. (1972) ATP levels in hamster spermatozoa during capacitation in vitro. Biol. Reprod. 9, 361-369.

Tsunoda, Y. \& Chang, M.C. (1975) In vitro fertilization of rat and mouse eggs by ejaculated spermatozoa and the effect of energy sources on in vitro fertilization of rat eggs. $J$. exp. Zool. 193, 79-86.

Turner, T.T., D'Addario, D. \& Howards, S.S. (1978) Further observations on the initiation of sperm motility. Biol. Reprod. 19, 1095-1101.

Williamson, J.R. \& Corkey, B.E. (1969) Assays of intermediates of the citric acid cycle and related compounds by fluorimetric enzyme methods. In Methods in Enzymology, Vol. 13, pp. 434-513. Ed. J. M. Lowenstein. Academic Press, New York.

Yedwab, G.A., Paz, G., Homonnai, T.Z., Menahem, P.D. \& Kraicer, P.F. (1976) The temperature, pH and partial pressure of oxygen in the cervix and uterus of women and uterus of rats during the cycle. Fert. Steril. 27, 304-309. 